\title{
Characterization of middle-ear condition of Oporto daycare children up-to 3 years-old: A cross sectional study
}

\author{
David Tomé ${ }^{\mathrm{a}}$, Ana Manuela Ferreira Silva Alexandrino ${ }^{\mathrm{b}, \mathrm{c}, *}$, \\ Rita Isabel Garrido Vieira Santos ${ }^{\mathrm{b}}$, Maria Cristina Damas Argel de Melo ${ }^{\mathrm{b}}$, \\ Daniel André Santos Costa ${ }^{\mathrm{b}}$, João Pinto Ferreira ${ }^{\mathrm{c}, \mathrm{d}}$

\footnotetext{
${ }^{a}$ Department of Audiology, School of Allied Health Sciences of Porto (ESTSP), Polytechnic Institute of Porto (IPP), Portugal

${ }^{\mathrm{b}}$ Department of Physiotherapy, School of Allied Health Sciences of Porto (ESTSP), Polytechnic Institute of Porto (IPP), Portugal

${ }^{\mathrm{C}}$ Institute for Biomedical Sciences Abel Salazar (ICBAS), University of Porto, Portugal
} \\ d Otorhinolaryngology Department of Porto Hospital Center, Portugal
}

Keywords:

Tympanometric values

Eustachian tube dysfunction

Middle-ear effusion

Acute otitis media

Upper respiratory infection

Daycare children

\begin{abstract}
A B S T R A C T
Objective: The aim of this study was to determine tympanometric values of children who attend Oporto daycare centers and further analyze any relations with host and environmental factors.

Methods: Cross sectional study in a randomly selected sample of 117 daycare children up-to 3-years old from Oporto. Tympanometric measures were collected.

Results: Children presented in left ear (LE) a mean peak pressure (PP) of -156.53 daPa and a mean compliance of $0.16 \mathrm{~cm}^{3}$. Right ear (RE) revealed a PP of $-145.61 \mathrm{daPa}$ and a compliance of $0.19 \mathrm{~cm}^{3}$. Normal tympanograms (type A) had a lower frequency than abnormal tympanograms (type $B$ and type $C$ ). There was a positive association between age and compliance (LE: $p=0.016 ; \operatorname{RE}: p=0.013$ ) and between the presence of rhinorrhea and PP (LE: $p=0.002 ; \mathrm{RE}: p<0.05)$. Abnormal tympanograms were more frequent in Spring (RE: $p=0.009$ ), in younger children (LE: $p=0.03$ ) and in children that had rhinorrhea (LE: $p=0.002$; RE: $p=0.044$ ).

Healthy children had a mean PP of - 125.19 daPa and a mean compliance of $0.21 \mathrm{~cm}^{3}$ in LE and a mean PP of -144.27 daPa and a mean compliance of $0.22 \mathrm{~cm}^{3}$ in RE.

Conclusion: Tympanometric measures presented in this paper may be applicable to Oporto daycare children up-to 3 years-old. Most of daycare children revealed abnormal tympanograms. Age, rhinorrhea and season influenced children's middle-ear condition.
\end{abstract}

\section{Introduction}

Middle ear assessment has a substantial importance in audiology, otolaryngology and ENT (ear, nose and throat) services, especially in children, due to their considerable risk to develop acute otitis media (AOM) and otitis media with effusion (OME).

Abbreviations: AOM, acute otitis media; CSS, Clinical Severity Score; ETD, Eustachian tube dysfunction; LE, left ear; MEE, middle-ear effusion; PP, peak pressure; RE, right ear; URI, upper respiratory infection.
Single-frequency tympanometry $(226 \mathrm{~Hz})$ has been the standard practice and method to assess functional condition of the middle ear due to its simplicity, speed, straightforwardness and its reasonable accuracy in detecting otitis media. The use of this physiologic procedure is particularly important in infants and children, due to high incidence of ear problems in the first years of life [1].

AOM is one of the most common bacterial infectious diseases in childhood with quick onset but rare under three months old. OME is middle ear fluid that remains after the acute infection is gone or it can arise asymptomatically without a preceding infection [2]. Literature described some risk factors such as: age $<2$ years, male gender, decreasing in breastfeeding, increasing antibiotic resistance and early attending daycare centers [3-7]. Additionally, AOM and OME in children are associated with upper respiratory infections (URI) as they create nasopharynx congestion and 
negative pressure in the middle ear, leading to Eustachian tube dysfunction (ETD) [8]. Some studies revealed that $30-60 \%$ of URI were complicated by AOM $[9,10]$.

Furthermore the risk for otitis media (OM) may be reduced substantially by avoiding frequent exposure to respiratory viruses (e.g., avoidance of daycare attendance) in the first year of life [10].

Nesti and Goldbaum [11] reported that children attending daycare centers exhibited two to three times greater risk of acquiring infections, which impacts on individual health and on diseases' dissemination through the community. Although there are some studies about the risk factors of Eustachian tube dysfunction in children, there is a lack of information about tympanometry normative data in Portuguese younger children and also about the influence of specific environments, such as daycare centers, in middle ear condition, in order to contribute toward more successful prevention and treatment of AOM and OME. Moreover it is important to verify if a single-frequency tympanometry ( $226 \mathrm{~Hz}$ probe tone) procedure at a daycare center can be considered a screening tool to detect initial stages of exposure to pathogens that result in colds and flu and/or otitis media.

The aim of this study was to determine tympanometric values of children who attend Oporto daycare centers and further analyze any relations with host and environmental factors.

\section{Methods}

After Ethics Committee of Oporto University's approval (No. 13/ CEUP/2011), six daycare centers were randomly selected from Oporto. Then, daycare centers' administrators were contacted in order to give their formal consent. The formal caregivers were informed about the aims and procedures of the study and expressed their formal consent by signing the Informed Consent according to Helsinki's Declaration.

A social demographic questionnaire with inclusion and exclusion criteria was delivered to the children's caregivers of the six daycare centers. Inclusion criteria were defined as: children up-to 3 years-old, both gender and both ears with normal tympanic membranes regarding the color, position and without detectable middle ear fluid by otoscopy. Premature children, neuromuscular or chronic cardiopulmonary diseases and children submitted to ear, nose and throat (ENT) surgery, with obstructive ear wax or history of grommets were excluded, as well as those who did not attend on the day of evaluation or did not complete the assessment $[12,13]$.

From an initial group of 125 children 8 were excluded after the application of these criteria and a final sample of 117 children was obtained.

From February to May 2013 all children were submitted to a standard protocol by the same audiologist which consisted of otoscopy followed by tympanometry. The child was on the educator's lap and his head was sustained against the educator's chest.

For tympanometry it was used a Hand Held Impedance Audiometer MT10 (Interacoustics ${ }^{\circledR}$ USA) calibrated on November 22, 2010, according to Food and Drug Administration (FDA) requirements, with a $226 \mathrm{~Hz}$ probe tone.

The classification system used in this study followed the classification developed by Liden and Jerger [14,15]. There are three main types of tympanograms: type A (normal middle ear compliance $\geq 0.2 \mathrm{~cm}^{3}$, pressure $\geq-100 \mathrm{daPa}$ ); type B (middle ear with fluid and/or having high impedance - compliance $<0.2 \mathrm{~cm}^{3}$ with no apparent peak pressure) and type $C$ (negative pressure, no fluid - compliance $\geq 0.2 \mathrm{~cm}^{3}$, pressure $<-100 \mathrm{daPa}$ ) [16].

Clinical Severity Score (CSS) was cultural adapted to Portuguese and used to measure the respiratory children's condition. It has an internal consistency of Cronbach's $\alpha=0.72$ and a good test-retest reliability (ICC 2,1 $=0.63$ ). CSS is a caregiver's perception tool that assesses child's clinical parameters such as dyspnea, breathing sounds, adventitious sounds, daily expectoration, cough, nutrition, fever and rhinorrhea. Each signal/symptom is rated with 1 point (normal), 2 points (moderate) or 3 points (severe) according to severity degree. It is obtained a final score between 8 and 24 (8normal index; 9-16 - moderate index; 17-24 - severe index) [17].

All statistical analysis were carried out using IBM $^{\circledR}$ SPSS $^{\circledR}$ Statistics 20 for Windows $7^{\mathbb{R}}$ with a confidence interval of $95 \%$ (significance level of $\alpha=0.05$ ) [18].

Paired $t$-tests were used for the comparison between tympanometric and environmental variables and children's characteristics. $T$-tests for independent samples and a one-way analysis of variance were used for different subgroups assessment. Chisquare test was used for comparison between tympanogram type, environment and anthropometric children characteristics [18].

\section{Results}

The final sample of this study was composed by 117 children aged between 3 and 36 months, with a mean age of $23.4( \pm 9.4)$ months and most children were male (62.4\%). Considering Body Mass index (BMI) percentile, $38 \%$ of the children were on the $50 \%$ percentile and $20 \%$ on the $25 \%$ percentile.

It was observed a mean middle-ear peak pressure (PP) of $-156.53 \mathrm{daPa}(S D=104.30)$ for left ear and $-145.61 \mathrm{daPa}$ $(S D=103.64)$ for right ear. Mean tympanic membrane compliance was a about $0.16 \mathrm{~cm}^{3}(S D=0.15)$ in the left ear and $0.19 \mathrm{~cm}^{3}$ $(S D=0.17)$ in right the ear.

It was observed a significant relation between age and both middle-ears compliance (LE: $p=0.016$; RE: $p=0.013$ ) and also between rhinorrhea presence and PP (LE: $p=0.002$; RE: $p=0.044$ ) (Table 1).

Only $25 \%$ of the children were classified with a healthy respiratory condition according to CSS' classification (CSS $=8$ ). These children had a mean PP of -125.19 daPa, a mean compliance of $0.21 \mathrm{~cm}^{3}$ in LE and a mean PP of $-144.27 \mathrm{daPa}$ and a mean compliance of $0.22 \mathrm{~cm}^{3}$ in $\mathrm{RE}$.

There was a higher frequency of type A (normal tympanogram) in both ears (38.5\% in left ear and $37.6 \%$ in right ear), followed by type $\mathrm{B}(38.4 \%$ in left ear and $34.2 \%$ in right ear) and type C $(23.1 \%$ in left ear and $28.2 \%$ in right ear).

Abnormal tympanograms were more frequent in Spring in children's right ear $(p=0.009)$, in younger children's left ear $(p=0.031)$ and in left ear of children that had with rhinorrhea $(p=0.025)$ (Table 2).

\section{Discussion}

The purpose of the present study was to characterize middleear condition of daycare children's up-to 3 years-old according to environmental and host characteristics. In this study, children who attended daycare centers had lower mean peak pressure (PP) and compliance values comparing to those suggested by different authors [12,16]. Palmu [19] states that PP values lower than -100 daPa have always been considered a negative pressure state in the middle ear. Nevertheless he considered that tympanometric negative PP values may also be interpreted as normal dry ear, especially if it will be taken into account the effect of some environmental and host characteristics, such as season, age or health status [19].

In fact, this study sample was obtained from local daycare centers, which are considered to be a very important risk factor for developing upper respiratory infections (URI), generally associated with Eustachian tube dysfunction (ETD) $[11,16]$. However there is a 
Table 1

Mean peak pressure and compliance values according to environmental and host factors (CSS: Clinical Severity Score).

\begin{tabular}{|c|c|c|c|c|c|c|}
\hline & & \multirow[b]{2}{*}{$N$} & \multicolumn{2}{|c|}{ Peak pressure (daPa) } & \multicolumn{2}{|c|}{ Compliance $\left(\mathrm{cm}^{3}\right)$} \\
\hline & & & Left ear & Right ear & Left ear & Right ear \\
\hline \multirow[t]{3}{*}{ Gender } & Male & 73 & -162.56 & -140.03 & 0.18 & 0.15 \\
\hline & Female & 44 & -146.52 & -154.86 & 0.14 & 0.17 \\
\hline & $p$ & - & 0.725 & 0.957 & 0.278 & 0.336 \\
\hline \multirow[t]{3}{*}{ Season } & Winter & 57 & -140.86 & -134.26 & 0.17 & 0.17 \\
\hline & Spring & 60 & -171.42 & -156.38 & 0.16 & 0.19 \\
\hline & $p$ & - & 0.114 & 0.250 & 0.641 & 0.379 \\
\hline \multirow[t]{4}{*}{ Age } & $<1$ year & 22 & -189.05 & -141.77 & 0.11 & 0.12 \\
\hline & $1-2$ years & 32 & -139.75 & -129.88 & 0.13 & 0.15 \\
\hline & $>2$ years & 63 & -153.70 & -154.94 & 0.20 & 0.23 \\
\hline & $p$ & - & 0.304 & 0.524 & 0.016 & 0.013 \\
\hline \multirow[t]{3}{*}{ Respiratory children's condition } & Normal $(\mathrm{CSS}=8)$ & 26 & -125.19 & -144.27 & 0.21 & 0.22 \\
\hline & Moderate $(8<$ CSS $<16)$ & 91 & -165.48 & -145.99 & 0.15 & 0.17 \\
\hline & $p$ & - & 0.082 & 0.941 & 0.057 & 0.185 \\
\hline \multirow[t]{3}{*}{ Rhinorrea presence } & Yes & 71 & -180.62 & -161.27 & 0.16 & 0.15 \\
\hline & No & 45 & -120.04 & -122.22 & 0.21 & 0.17 \\
\hline & $p$ & - & 0.002 & 0.044 & 0.444 & 0.161 \\
\hline
\end{tabular}

Table 2

Tympanogram type's frequencies (\%) according to environmental and host characteristics. (CSS: Clinical Severity Score).

\begin{tabular}{|c|c|c|c|c|c|c|c|}
\hline \multirow[t]{2}{*}{ Tympanogram type } & & \multicolumn{3}{|l|}{ Left ear } & \multicolumn{3}{|c|}{ Right ear } \\
\hline & & A & B & C & A & B & C \\
\hline \multirow[t]{3}{*}{ Gender } & Male & 40 & 37 & 23 & 38 & 34 & 28 \\
\hline & Female & 36 & 41 & 23 & 36 & 34 & 30 \\
\hline & $p$ & 0.969 & 0.097 & & & & \\
\hline \multirow[t]{3}{*}{ Season } & Winter & 42 & 44 & 14 & 40 & 44 & 16 \\
\hline & Spring & 35 & 33 & 32 & 35 & 25 & 40 \\
\hline & $p$ & 0.079 & 0.009 & & & & \\
\hline \multirow[t]{4}{*}{ Age } & $<1$ year & 18 & 55 & 27 & 28 & 36 & 36 \\
\hline & $1-2$ years & 38 & 50 & 12 & 34 & 50 & 16 \\
\hline & $>2$ years & 46 & 27 & 27 & 43 & 25 & 32 \\
\hline & $p$ & 0.031 & 0.107 & & & & \\
\hline \multirow[t]{3}{*}{ Respiratory children's condition } & Normal $(\mathrm{CSS}=8)$ & 54 & 23 & 23 & 46 & 27 & 27 \\
\hline & Moderate $(8<$ CSS $<16)$ & 34 & 43 & 23 & 35 & 36 & 29 \\
\hline & $p$ & 0.132 & 0.544 & & & & \\
\hline \multirow[t]{3}{*}{ Rhinorrhea presence } & Yes & 28 & 44 & 28 & 31 & 34 & 35 \\
\hline & No & 53 & 31 & 16 & 47 & 35 & 18 \\
\hline & $p$ & 0.025 & 0.093 & & & & \\
\hline
\end{tabular}

lack of studies that states the influence of a risk environment, such as daycare centers, in tympanometric values of young children.

In this study, more than a half of the children had rhinorrhea signs and this is considered to be one of the initial signs of acute URI, as well as fever and cough [20]. There was found a significant association between lower PP values and rhinorrhea presence which was consistent with Palmu's study [12]. Furthermore there was a higher frequency of type A (healthy) tympanograms in children without rhinorrhea comparing to those with rhinorrhea consistent with Revai et al. [10] when they reported that 55\% of tympanograms during the first week of URI were abnormal and at least one abnormal tympanogram was documented during $76 \%$ of the URI episodes. This occurs because ETD generally is a common endpoint for viral-induced pathology, including increased production and stasis of secretions, swelling of respiratory mucosa of the Eustachian tube (resulting in intrinsic obstruction), and enlargement of adenoids (resulting in extrinsic obstruction). These cause negative middle ear pressure which predispose to middle ear effusion by aspiration or nasopharyngeal's insufflations [21].

Apart from rhinorrhea there are another anamnestic and clinical signs of URI such as cough, fever, expectoration and other health condition parameters analyzed by the Clinical Severity Score (CSS) and tympanometric values. There were no significant results; however, it could be observed that children with higher
CSS had lower peak pressure and compliance values. It was also observed a higher frequency of type A tympanograms in children with a healthy respiratory clinical condition and a higher frequency of type B tympanograms in children with an unhealthy clinical condition. The absence of statistical significance may be due to some CSS limitations as it evaluates some signs/symptoms that are related to children's general health condition and not only respiratory signs [22]. Still mean peak pressure and compliance found in healthy children (CCS $=8$ ) were inferior to those found by Palmu [12] suggesting that environmental characteristics may influence tympanometric values.

High frequency of type B in both ears observed in the study might be due to the large developmental differences that are apparent using low-frequency probe tone between infants with less than 12 months and older [2]. Multifrequency tympanometry with higher frequencies $(660,1000$ and $2000 \mathrm{~Hz}$ ) seems to increase sensitivity and specificity of middle ear disorders identification in infants under 12 months old, and must be considered in a future study [12]. In winter, nasopharyngeal colonization with Streptococcus pneumoniae and parental occupation (poor socioeconomic status) are the most important risk factors for URI among local infants [23]. In fact, several studies suggest a seasonal predominance of AOM which is coincidental with that of URIs [9,16]. In this study there was not found any association between season and PP 
nor compliance values, even though in spring there were observed lower pressure and compliance values comparing to winter. Moreover, there was a significant $5 \%$ lower frequency of type A tympanograms in Spring (in right ear) and taking into account Heikkinen and co-workers' findings [24] revealing that in each week between mid-November and the end of April, influenza viruses accounted for at least $5 \%$ of all respiratory infections in children. This suggests that influenza viruses may circulate in the community at substantial levels much longer than previously thought.

Host characteristics such as gender and age must be considered in order to analyze their influence on middle ear's condition. In relation to gender there was not found any association with tympanometric values and there was no consistent profile between ears. Even though Nair and colleagues [25] revealed that URI have a higher occurrence in boys than girls, generally attributed to gender differences concerning respiratory system developing. Regarding ETD it is suggested that boys had a higher risk than girls, having a higher unadjusted mean cumulative proportions of days with middle-ear effusion, and having a higher frequency of tympanostomy tube insertion. Moreover Palmu [12] found better results for compliance in boys and worse results for PP, but these differences seem to reduce with age. The author sustained that higher values of compliance were associated with male gender and higher birth weight, probably reflected by the size of the middle ear and tympanic membrane $[12,13]$.

The significant association observed between children's age and tympanometric variables as younger children are at particular risk of abnormal tympanograms because their Eustachian tube is relatively shorter, narrower, more compliant and more horizontal than that of an older child or adult $[10,26]$. These differences make the tube vulnerable to collapse contributing to partial or total obstruction of the lumen and ultimately AOM [10]. In this study there was a higher frequency of type A tympanograms in older children, as reported by Moody and co-workers [16]. Nevertheless Revai and colleagues [10] found similar results during URI episodes, revealing that young children (6-11 months of age) were more likely to have type B tympanogram, whereas older children (24-47 months of age) had type C tympanograms. This may be one of the reasons why AOM incidence and prevalence decreases with age. In fact, the peak age for AOM is considered to be between 6 and 18 months, because the Eustachian tube in young children is most vulnerable making them most susceptible to AOM especially after URI $[5,9,10]$.

\section{Conclusion}

Data values related to peak pressure and compliance presented in this paper may be applicable to Oporto daycare children up-to 3 years-old. Most of daycare children revealed an abnormal tympanogram. Age, rhinorrhea and season influenced tympanometric parameters. Assessing and implementing environmental screening routines it is important to found early dysfunctions, such as daycare centers contributing to reduce the health and social impacts of acute otitis media, Otitis Media with Effusion AOM, OME and URI.

\section{Acknowledgments}

Thanks to all participants, children, caregivers and educators, to Statistical Department colleagues and to Dr. Paula Lopes, Director of Department of Audiology.

\section{References}

[1] Joint Committee on Infant Hearing, Position statement: principles and guidelines for early hearing detection and intervention programs, Pediatrics 120 (2007) 898921.

[2] L.L. Hunter, N. Shahnaz, Acoustic Immitance Measures: Basic and Advanced Practice, Plural Publishing, San Diego, 2014, pp. 127-158.

[3] D.W. Teele, J.O. Klein, B. Rosner, Epidemiology of otitis media during the first seven years of life in children in greater Boston: a prospective, cohort study, J. Infect. Dis. 160 (1) (1989) 83-94.

[4] J.L. Paradise, H.E. Rockette, D.K. Colborn, D.K. Bernard, B.S. Smith, C.G. Kurs-Lasky, et al., Otitis media in 2253 Pittsburgh-area infants: prevalence and risk factors during the first two years of life, Pediatrics 99 (3) (1997) 318-333.

[5] K.A. Daly, G.S. Giebink, Clinical epidemiology of otitis media, Pediatr. Infect. Dis. J. 19 (5 Suppl.) (2000) S31-S36.

[6] H. Monobe, T. Ishibashi, Y. Fujishiro, M. Shinogami, J. Yano, Factors associated with poor outcome in children with acute otitis media, Acta Otolaryngol. 123 (5) (2003) 564-568

[7] S. Keyhani, L.C. Kleinman, M. Rothschild, J.M. Bernstein, R. Anderson, M. Simon, et al., Clinical characteristics of New York City children who received tympanostomy tubes in 2002, Pediatrics 121 (1) (2008) 24-33.

[8] D.M. Duarte, C. Botelho, Clinical profile in children under five year old with acute respiratory tract infections, J. Pediatr. (Rio J) 76 (3) (2000) 207-212.

[9] T. Chonmaitree, K. Revai, J.J. Grady, A. Clos, J.A. Patel, S. Nair, et al., Viral upper respiratory tract infection and otitis media complication in young children, Clin. Infect. Dis. 46 (6) (2008) 815-823.

[10] K. Revai, J.A. Patel, J.J. Grady, T. Chonmaitree, Tympanometric findings in young children during upper respiratory tract infections with and without acute otitis media, Pediatr. Infect. Dis. J. 27 (4) (2008) 292-295.

[11] M.M. Nesti, M. Goldbaum, Infectious diseases and daycare and preschool education, J. Pediatr. (Rio J). 83 (4) (2007) 299-312.

[12] A. Palmu, H. Puhakka, H. Huhtala, A.K. Takala, T. Kilpi, Normative values for tympanometry in 7- and 24-month-old children, Audiology 40 (4) (2001) $178-184$.

[13] A. Palmu, T. Rahko, Normative values for tympanometry in 4-5-year-old children, Int. J. Audiol. 42 (6) (2003) 327-330.

[14] G. Liden, The scope and application of current audiometric tests, J. Laryngol. Otol. 83 (1969) 507-520.

[15] J.F. Jerger, Clinical experience with impedence audiometry, Arch. Otolaryngol. 92 (1970) 311-324.

[16] S.A. Moody, C.M. Alper, W.J. Doyle, Daily tympanometry in children during the cold season: association of otitis media with upper respiratory tract infections, Int. J. Pediatr. Otorhinolaryngol. 45 (2) (1998) 143-150.

[17] G. Postiaux, J. Bafico, R. Masengu, J. Lahaye, Paramètres anamnestiques et cliniques utiles au suivi et à l'achèvement de la toilette bronchopulmonaire du nourrisson et de l'enfant, Ann. Kinésithér. 18 (1991) 117-124.

[18] J. Maroco, Análise Estatística Com Utilização SPSS, 3rd ed., Edições Sílabo, Lisboa, 2007.

[19] A. Palmu, R. Syrjänen, T. Kilpi, H. Pursiainen, H. Puhakka, T. Rahko, et al., Negative pressure tympanograms in children less than 2 years of age - different bacterial findings in otitis media by tympanometric results, Int. J. Pediatr. Otorhinolaryngol. 61 (1) (2001) 61-69.

[20] Y. Matsuzaki, N. Katsushima, Y. Nagai, M. Shoji, T. Itagaki, M. Sakamoto, et al., Clinical features of influenza C virus infection in children, J. Infect. Dis. 193 (9) (2006) 1229-1235.

[21] S.M. Antonio, D. Don, W.J. Doyle, C.M. Alper, Daily home tympanometry to study the pathogenesis of otitis media, Pediatr. Infect. Dis. J. 21 (9) (2002) 882-885.

[22] G. Postiaux, Fisioterapia respiratória pediátrica: o tratamento guiado por ausculta pulmonar, Artmed, Porto Alegre, 2004.

[23] V. Rupa, R. Isaac, A. Manoharan, R. Jalagandeeswaran, M. Thenmozhi, Risk factors for upper respiratory infection in the first year of life in a birth cohort, Int. J. Pediatr. Otorhinolaryngol. 76 (12) (2012) 1835-1839.

[24] T. Heikkinen, T. Ziegler, V. Peltola, P. Lehtinen, P. Toikka, M. Lintu, et al., Incidence of influenza in Finnish children, Pediatr. Infect. Dis. J. 22 (2003) S204-S206.

[25] H. Nair, E. Lau, W. Brooks, A. Seong, E. Theodoratou, L. Zgaga, et al., An evaluation of the emerging vaccines against influenza in children, BMC Public Health 13 (2013) S14.

[26] C. Bluestone, J. Klein, Physiology, pathopysiology and pathogenesis, in: B. Decker (Ed.), Otitis Media in Infants and Children, Canada, 2007, 41-72. 